\title{
From Research to Practice and Back: The Animation Tutor Project
}

\author{
Stephen K. Reed ${ }^{1,2}$
}

The Animation Tutor ${ }^{\mathrm{TM}}$ is a curriculum project that uses software to supplement instruction in courses such as intermediate algebra. Its purpose is to ground mathematical reasoning in concrete experiences through the use of interactive animation and the virtual manipulation of objects. This article summarizes how the project has progressed from research to practice and back. The first section shows how research helped implement six instructional objectives: emphasize interactivity with reflection, integrate multiple representations, reduce cognitive load, facilitate transfer, replace ineffective static images with animated images, and provide domain-specific knowledge. The last section illustrates the reciprocal nature of research and practice by describing how formative evaluations of the Animation Tutor ${ }^{\mathrm{TM}}$ program led to laboratory studies aimed at improving instructional materials and student strategies.

KEY WORDS: action; animation; mathematical reasoning; technology; tutor.

One of the challenges facing education is that many students lack the mathematical knowledge to perform well in courses that require quantitative reasoning. Even the successful learning of quantitative skills in a mathematics course does not guarantee transfer to other fields. As pointed out in the Benchmarks for Science Literacy:

Computation is the process of determining something by mathematical means. Its value is acknowledged by the prominence accorded mathematics in school systems everywhere. Unfortunately, that preferred status has not been matched by results. It turns out that being able to get correct answers to the problems at the end of the chapter or on a work sheet or test is no guarantee of problem-solving ability in real

\footnotetext{
${ }^{1}$ San Diego State University, San Diego, California.

${ }^{2}$ Correspondence should be addressed to Stephen K. Reed, CRMSE, 6475 Alvarado Road, Ste 206, San Diego, California 92120; e-mail: sreed@sunstroke.sdsu.edu.
} 
situations. That ought not to be surprising, given that in traditional mathematics teaching, problems lack interesting real-world contexts; that memorization of algorithms by drill is not matched by learning when to use them; that numbers are used without units or attention to significance; and that students receive little, if any, help in learning how to judge how good their answers are. (American Association for the Advancement of Science, 1993, p. 288)

The concern with improving mathematics instruction is evident not only in the Benchmarks but more recently in Project 2061, the reform initiative of the American Association for the Advancement of Science. An evaluation of 12 algebra textbooks by Project 2061 resulted in just 7 of the 12 textbooks being rated as adequate, with the potential for helping students learn algebra (Project 2061, 2000). Five other textbooks, including best sellers, were rated as having little potential for helping students learn algebra. Two of the recommendations resulting from the study were to use the Project 2061 evaluations to identify a textbook's strengths and weaknesses and to draw on a variety of resources to compensate for a textbook's weak areas.

The Animation Tutor ${ }^{\mathrm{TM}}$ is a curriculum project that uses software to supplement instruction in courses such as intermediate algebra. Its purpose is to ground mathematical reasoning in concrete experiences through the use of interactive animation and the virtual manipulation of objects. It currently consists of eight modules that each require about one hour of the student's time. Table I describes the modules. As shown in Table I, many of the modules apply mathematics to real-world content such as chemical kinetics, finance, and population growth. Readers are encouraged to view demonstrations of the modules by visiting the Animation Tutor website at http://www.sci.sdsu.edu/mathtutor/.

My initial interest in designing these modules stemmed from research that I conducted in the mid 1980s that was concerned with improving estimation skills (Reed, 1984, 1985; Reed and Evans, 1987; Reed and Saavedra, 1986). This article is a case study of how these, and more recent, findings have influenced the instructional design decisions. Although the emphasis is on how previous research influenced the initial design, I show how formative evaluations of the modules have influenced our redesign of ineffective instruction. I also discuss how the instructional design process has raised research questions.

Although the focus of these modules is on algebra word problems, this review does not emphasize designing a problem-solving environment for word problems. A recent article in this journal provides an excellent description for readers interested in this topic (Jonassen, 2003). My goal is to show how research influenced the implementation of more general 
Table I. Instructional Modules in the Animation Tutor Project

1. Animation Tutor: Average speed. Uses average speed as an example of a
weighted average problem. Multiple representations illustrate the constraint
that average speed can not exceed twice the slower speed (Reed et al., 2000).
Animation Tutor: Chemical kinetics. Presents two ideas that are fundamental to
calculus (area under a curve and a tangent to a curve) within a scientific context.
Introduces key ideas of chemical kinetics to provide the context (Tyner et al.,
2000).
Animation Tutor: Catch up. Includes problems in which one person or vehicle
catches another by traveling at a constant speed or a constant acceleration.
Applies ideas to determining a safe driving distance (Reed et al., 2001).
Animation Tutor: Personal finance. Emphasizes the distinction between simple
and compound interest as examples of linear and exponential growth.
Application to annuities (Hoffman and Reed, 2001).
Animation Tutor: Population growth. Requires estimating and adjusting
parameters to improve goodness-of-fit of linear and exponential models of
population growth. Investigates extrapolation to predict future growth (Reed
et al., 2002).
Animation Tutor: Dimensional thinking. Corrects students' tendency through
object manipulation to misapply proportional reasoning to areas and volumes.
Generalizes ideas to irregular shapes (Greer et al., 2002).
Animation Tutor: Task completion. Illustrates how the same equation applies
across a variety of problems that differ in story content. Shows different
methods for solving the same problem (Reed and Phares, 2003).
Animation Tutor: Leaky Tanks. Demonstrates how a simple (no leak) solution
can be adapted to solve more complex problems in which there is a bottom leak
or a side leak. The side leak solution combines the no-leak and bottom-leak
solutions (Reed et al., 2003).

instructional objectives that could apply to many different types of learning environments. The first section (From Research to Practice) describes these objectives:

- Encourage interactivity with reflection. Interaction with the software should encourage students to think deeply about the ideas in the instruction.

- Make connections among problem solutions. Problem solutions provide a basis for solving related problems if students can discover these relations.

- Integrate multiple representations. Students should see the interconnection among ideas that are expressed in different representations such as text, formulas, pictures, and graphs.

- Reduce cognitive load. Instructional material should not overwhelm the limited capacity of short-term memory.

- Replace ineffective static images with dynamic images. Animated images may be necessary to understand ideas that involve movement. 
- Provide domain-specific knowledge. Instruction on general strategies often requires specific content knowledge for effective use of the strategies.

Although these objectives guided the design of all the instructional modules, I focus on particular modules to illustrate how research influenced their formulation and implementation.

The second section (From Formative Evaluations to Laboratory Research) describes the methodology used to evaluate the modules, compares the methodology to design experiments, and advocates the experimental study of theoretical questions raised by the formative evaluations. The concluding section (From Practice to Research) illustrates the circular nature of research and practice by showing how questions raised by the curriculum design led to further laboratory investigations of both students' strategies and the developers' design decisions.

\section{FROM RESEARCH TO PRACTICE}

\section{Encourage Interactivity with Reflection}

A potential advantage of software over noninteractive instructional formats is that students can interact with the software. However, the opportunity for interaction is wasted if the interaction does not cause students to think more deeply about the material. The modules in the Animation Tutor series are designed to promote interaction and reflection, as illustrated by the Task Completion module.

Task completion problems require estimating or calculating how long it will take to complete some task, such as filling a tank or painting a fence. The design of the Task Completion module followed directly from research on estimation skills (Reed, 1984). My initial interest in instructional animation was primarily driven by students' unreasonable estimates to problems like this asking for the amount of time it would take two pipes to fill a tank:

A small pipe can fill an oil tank in 8 hours and a large pipe can fill it in 4 hours. How long will it take to fill the tank if both pipes are used at the same time?

One-third of the college students, half of whom had taken a college algebra class, estimated an arithmetic average (such as $6 \mathrm{hr}$ ) for these kinds of problems (Reed, 1984). I was alarmed by the large number of estimates indicating that it would take more time for two pipes to fill a tank than the faster pipe working alone. I thought that an easy way to improve estimates 
would be to allow students to compare a simulation of the two pipes with a simulation of the faster pipe working alone. They could therefore judge the amount of time saved by adding a second pipe.

The attempt to improve students' estimates through simulations turned out to be more challenging than anticipated, and several iterations of the instruction were needed (Reed, 1985). One modification of the initial design showed students the two simulations at the same time so they would not have to rely on memory for making comparisons. Another change required them to estimate an answer after viewing each simulation, such as the time required to fill the tank when an 8-hr pipe and a 4-hr pipe are both used. These estimates were not scored for accuracy but encouraged students to attend closely to each pair of simulations. Estimation skill improved from pre- to posttesting following these modifications.

Although the instruction was successful, I took a more interactive approach in designing the Task Completion module in line with research studies that demonstrated the effectiveness of interactive animation. An early review of 13 instructional animation studies by Rieber (1990) resulted in his concluding that animation's greatest contributions may lie in its interactive graphic applications. More recent reviews have also emphasized the positive effects of interactivity (Tversky et al., 2002). The interactivity enables students to control the animation rather than to simply observe simulations that are not responsive to student input.

Interactive animation in the Animation Tutor modules allows students to evaluate the accuracy of an estimated or calculated answer by testing it in a simulation. Figure 1 illustrates this approach for a task completion problem. The instruction simulates an estimate by showing how much of the tank is filled, including the overflow tank if the estimate is too large. This visual feedback helped students improve their estimates on successive trials for each problem by showing them the outcome of their estimates (Reed et al., 2002).

The findings, however, raised several questions about the instruction. One concern was whether students use this feedback in a reflective manner. Did students use sophisticated strategies in revising their estimates or did they use trial and error? A second concern was whether animation contributes to successful revisions. Students watch a simulation of the tank filling, but the key information is where it stops filling. If students saw a static picture of where the tank stopped filling, would this information be as effective as viewing the entire simulation? These questions are answered later in the article when examining how the evaluation of instructional interventions can lead to new research questions (Reed and Hoffman, 2004). 


\section{Make Connections Among Problem Solutions}

An important skill in becoming a good problem solver is the ability to apply the solution of a problem to related problems (Barnett and Ceci, 2002). Research on the transfer of solutions across word problems by adapting and abstracting the solutions has also contributed to the design of the instructional materials (Reed, 1993, 1999). The Animation Tutor modules allow students to practice both estimating and calculating answers to problems. For example, after estimating how long it would take to fill the tank in Fig. 1, students are shown a method for calculating the exact answer.

The initial version of the Task Completion module emphasized adapting solutions by using the solution of a simple problem as the basis for estimating and calculating answers to more complex problems. The more complex problems required finding completion times for tanks that had (1) a leak in the bottom, (2) a leak in the side, and (3) two pipes that began filling at different times. However, there are many variations of task completion problems besides filling tanks. The development of another module

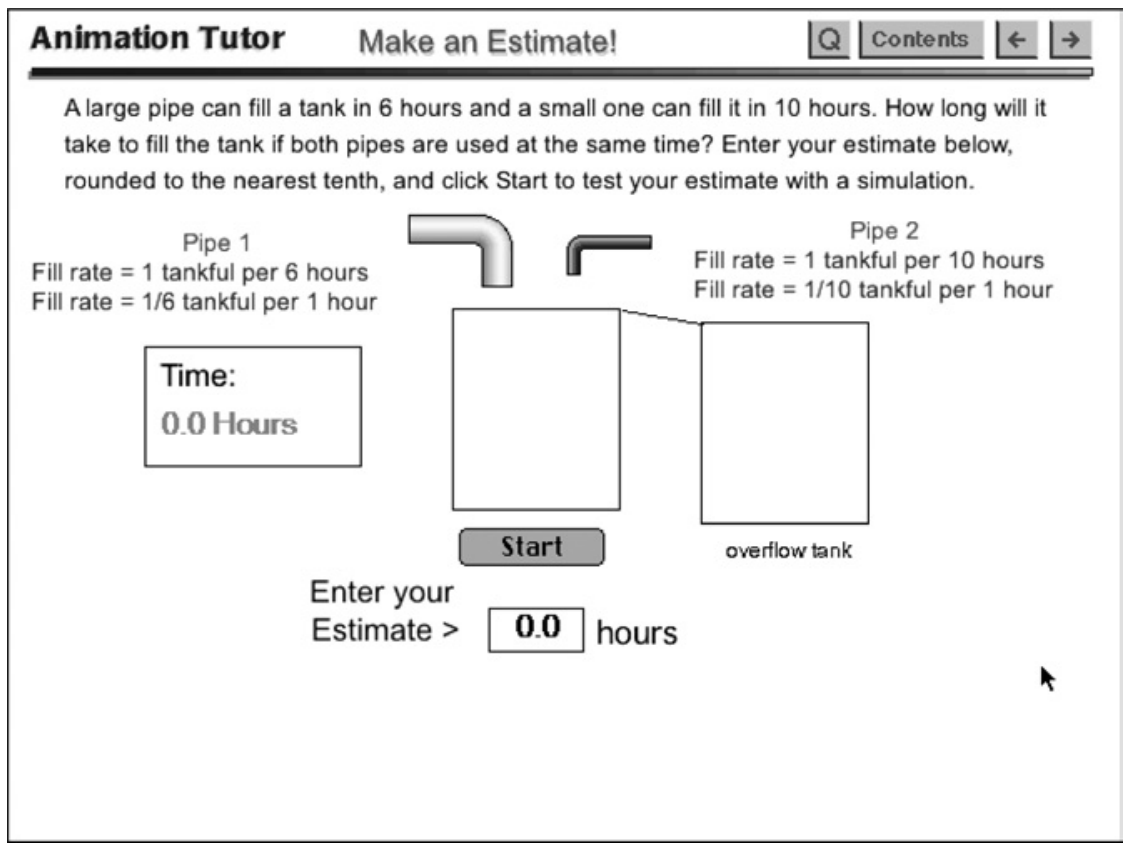

Fig. 1. Example of a tank-filling estimation in which students receive feedback by observing how much of the tank(s) fills. 
therefore emphasizes abstracting solutions across isomorphic problems that had the same solution but different story content.

The new Task Completion module (the original was renamed the Leaky Tanks module) demonstrates how problems with different story content can be solved by the same equation:

$$
\text { Rate }_{1} \times \text { Time }_{1}+\text { Rate }_{2} \times \text { Time }_{2}=\text { Tasks, }
$$

in which $\mathrm{Rate}_{1}$ and Time ${ }_{1}$ are the rate and time of the first pipe (worker, traveler), Rate $_{2}$ and $\mathrm{Time}_{2}$ are the rate and time of the second pipe (worker, traveler), and Tasks is the number of tasks to be completed. The three contexts are two pipes filling a tank, two workers painting a fence, and two people traveling toward each other to meet as in the following problem:

Sally and Maria decide to exchange homework assignments. Sally can walk to Maria's house in 4 minutes and Maria can walk to Sally's house in 3 minutes. How long will it take them to meet if they both leave their houses at the same time and walk toward each other?

The similarity of the traveler problem to the other two problems (pipe, worker) is particularly challenging because students tend to classify it as a distance-rate-time problem rather than as a "work" problem (Reed, 1987). The Task Completion instruction therefore builds on perceptual approaches to transfer (Greeno et al., 1993) that show the similarity between the painter and walker problems. As illustrated in Fig. 2, the simulation of the painter problem shows two painters working toward each other to meet, as the walkers do to exchange homework. There is evidence that increasing the similarity of static diagrams across problems facilitates transfer (Chen, 1995), but there is a need for more research on whether increasing the similarity of simulations enhances transfer, as implied by the affordance-activity approach proposed by Greeno et al. (1993).

Recent work by Goldstone and Sakamota (2002) indicates that designing animation to encourage transfer may be a challenging task. They found that using color to emphasize similarities across analogous simulations hindered transfer for participants who performed relatively poorly on the initial simulation, perhaps because the color cue placed too great an emphasis on superficial similarities. It is also possible that the convergence of painters in Fig. 2 might create superficial similarity between problems. Students might use convergence to transfer solutions across these particular problems but fail to transfer across other isomorphic versions of work and distance problems that do not involve convergence. As argued by Goldstone and Sakamota (2002), there is a need for research on how to best design instructional simulations because of their increasing importance in teaching difficult, abstract concepts. 


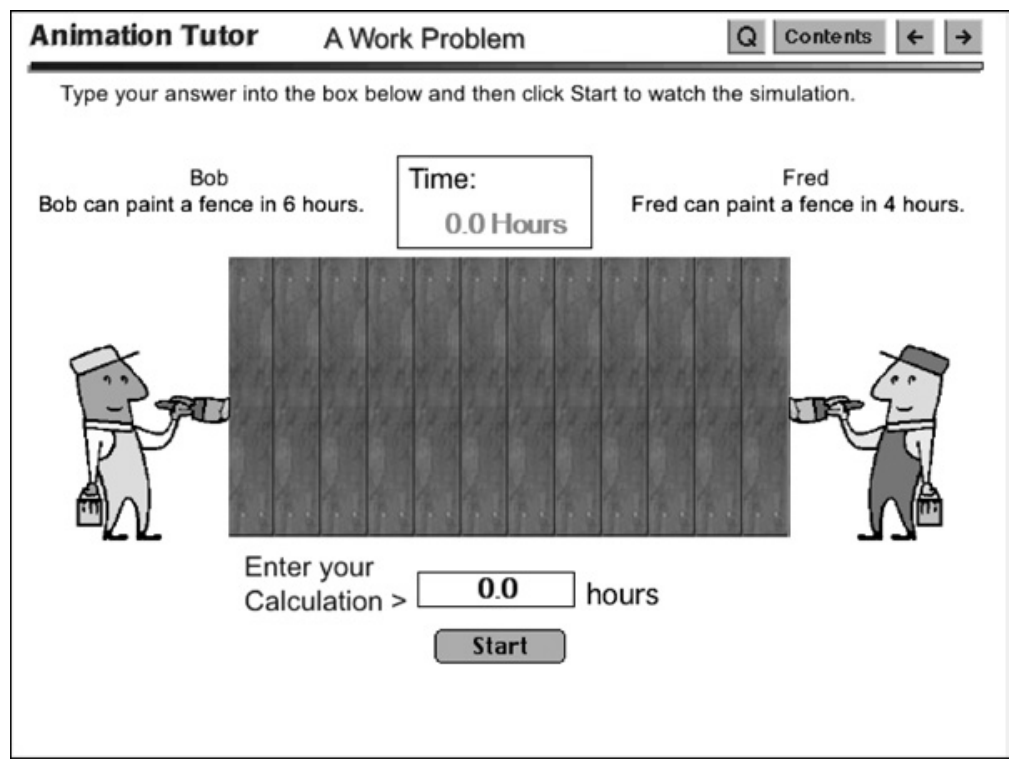

Fig. 2. Simulation of the painter problem shows a convergence of the two painters to enhance its similarity to the convergence of two objects in a distance-rate-time problem.

The similarity among the three isomorphic versions of the task completion problems is further developed in the Task Completion module by showing how the delay in one of the pipes corresponds to the delay in the start time of one of the walkers. Solving these delay problems provides another opportunity for students to compare problem solutions. Although making connections has been most extensively studied for the transfer of solutions across problems, it can also apply to alternative solutions to the same problem. In response to the question of "What should connections look like in grades 9 through 12?," the Principles and Standards for School Mathematics (NCTM, 2000) proposes that students should develop a deeper understanding that there is more than one method for solving a problem.

The Task Completion module provides two methods for solving delay problems. One approach is to construct a single algebraic equation that represents the amount of time for each pipe (or walker). A second approach is a decomposition method that calculates how much of the task is completed by the beginning pipe (walker), and how much time it takes both pipes (walkers) to complete the remainder of the task. As demonstrated by Koedinger and Tabachneck (1994), students who knew more than one strategy and switched strategies when they reached an impasse 
were more successful in solving word problems than students who used only a single strategy. Providing alternative methods is therefore consistent with both the NCTM recommendations and with the findings of Koedinger and Tabachneck.

\section{Integrate Multiple Representations}

Providing alternative methods for solving problems can be supplemented with providing alternative representations for thinking about problems. Examples of alternative representations include equations, static pictures, animations, text, and graphs. The use of multiple representations is illustrated in the Average Speed module. Many algebra word problems, including task completion problems, can be solved by using a weighted average in which two numbers are differentially weighted in calculating the answer (Reed, 1984). Calculating the average speed of a round trip is a prototypical example of a weighted average problem, but most students give an unweighted (arithmetic) average to the following kinds of problems:

Flying east between two cities, a plane's speed is $150 \mathrm{mph}$. On the return trip, it flies $300 \mathrm{mph}$. Find the average speed for a round trip (Reed, 1984).

The correct answer is $200 \mathrm{mph}$ and is found by weighting the two speeds by the relative amount of time spent traveling at those speeds. Because the pilot spends twice as much time traveling at $150 \mathrm{mph}$ : Average Speed $=2 / 3 \times 150 \mathrm{mph}+1 / 3 \times 300 \mathrm{mph}=200 \mathrm{mph}$.

The design of the Average Speed module was influenced by research that demonstrated the effectiveness of providing animation-based feedback for helping students improve their estimates of average speed and learn the counterintuitive constraint that the average speed can not exceed twice the slower speed (Reed and Saavedra, 1986). Its initial application is to reveal the common misconception that the average speed of a round trip is not the arithmetic average of the two speeds. As illustrated in Fig. 3, one car simulated the two speeds of a round trip and a second car (leaving at the same time) simulated the estimated average speed. Students were told that if their estimate were correct, both cars would return at the same time. None of the 25 students in an intermediate algebra class gave a correct answer to this problem and the animation revealed their error (Reed and Jazo, 2002). A second function of animation is to provide visual feedback to allow students to improve their estimates. A third function is to allow students to check the correctness of their calculations to problems in the same way that they check the accuracy of their estimates. A fourth function is to demonstrate the consequences of providing an estimate that exceeds twice the slower 


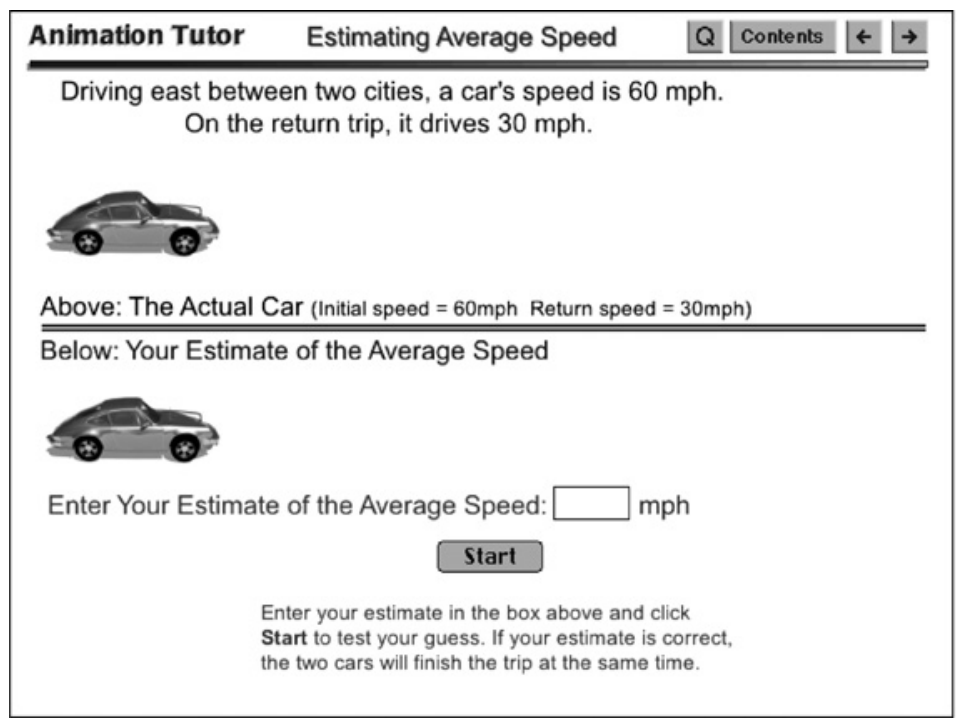

Fig. 3. Example of an average speed estimation in which students receive feedback by comparing a simulation of the problem with a simulation of their estimate.

speed by showing that an object moving at this speed will complete the entire round trip before the object moving at the slower of the two speeds arrives at its initial destination. A fifth function is to provide concrete examples to serve as data points for constructing a graph.

Although animation provided the foundation for the instruction, it was combined with other representations to gain the advantages of multiple representations. The three main advantages of multiple representations according to Ainsworth (1999) are to provide complementary roles, constrain interpretation, and construct a deeper understanding. Representations have complementary roles when there are differences in either the information that each contributes or in the processes that each supports. For example, the Average Speed module provides several different representations for explaining why the average speed cannot exceed twice the slower speed. Learners can view the asymptote in the graph, use the conception of speed as the ratio of total distance to total time, or study the limit of an algebraic function. One of the advantages of providing representations that complement each other is that learners may differ in their preferences for a certain representation. When asked which of these approaches was the most helpful for explaining the constraint on average speed, 10 students selected the algebraic approach, 8 students selected the conceptual approach, and 6 students selected the graphic approach (Reed and Jazo, 2002). The diversity 
of their preferences suggests that the complementary roles of these representations were helpful.

A second advantage of multiple representations is that one representation can be used to constrain the interpretation of a second representation. Graphs are able to show patterns in data but this advantage is lost if students have trouble interpreting graphs. Reed and Saavedra's (1986) finding that simulations were more effective than graphs can be applied to instruction by grounding the points on the graph in concrete examples. The examples consisted of four simulation problems in which students estimated the speed of the round trip when the initial speed was $5 \mathrm{mph}$ and the return speed was either (1) $2 \mathrm{mph}$, (2) $10 \mathrm{mph}$, (3) $20 \mathrm{mph}$, or (4) $45 \mathrm{mph}$. After showing the accuracy of an estimate in the simulation, the estimate and correct answer were plotted on the graph, as illustrated in Fig. 4 for the first three examples. The correct answers remained plotted on the graph and were connected by a curve after the last problem. Students were then asked to report the pattern illustrated by the curve and to make inferences about how the slower speed of a round trip limits the average speed. Combining animated and graphic representations constrains the interpretation of the graph by linking points on the graph to observed events.

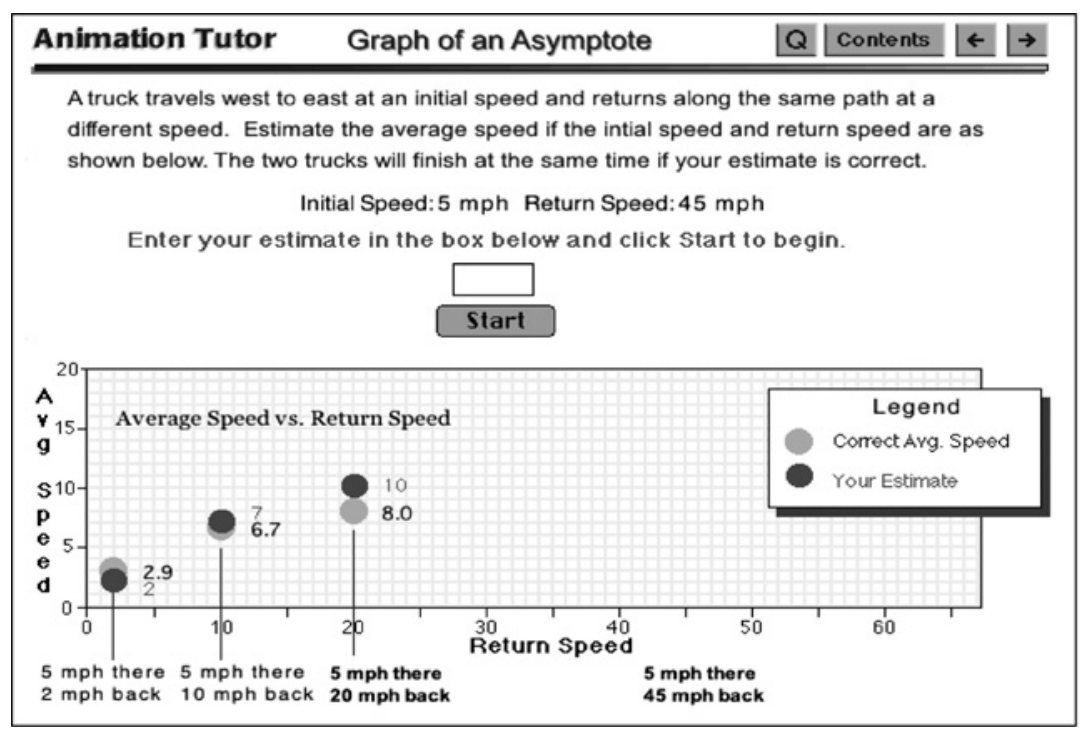

Fig. 4. A student's answers to an ordered series of four problems are plotted with correct answers to reveal an asymptote of a function. 
The third advantage of multiple representations is to promote a deeper understanding of the instructional material. In addition to using animation and graphs to illustrate the concept of average speed as a weighted average, the Average Speed module uses a conceptual explanation based on the definition of speed as total distance divided by total time. This mathematical representation provides a rationale for why a car traveling at two different speeds would return from a round trip at the same time as a car traveling at a weighted (by time) average of the two speeds. The animation of this mathematical relationship provides visual feedback for improving estimates and calculations of average speed. It is, therefore, important that students understand the reason behind it.

\section{Reduce Cognitive Load}

A potential problem in coordinating multiple representations is that the cognitive demands may overwhelm short-term memory capacity. According to Sweller's (1994) cognitive-load theory, good instructional design reduces cognitive load to a manageable level. For example, when studying a geometrical proof, students often need to integrate information presented in both a diagram and a text. Because it requires mental effort to integrate information presented in the two representations, cognitive load can be reduced by designing worked examples that carefully relate the steps in the proof to the diagram. Physically integrating the text and diagram avoids a split-attention effect caused by shifting attention between the text and diagram. Another example of reducing the split-attention effect in multimedia learning is to present a verbal narrative simultaneously with a diagram to reduce the cognitive effort required to integrate the two representations (Mayer, 2001). Learners can listen to an explanation of the diagram without having to shift their attention between the diagram and written text.

Bob Hoffman and I used research on the split-attention effect to redesign the Personal Finance module when a formative evaluation revealed that students were unable to identify the correct formulas for simple and compound interest after studying graphic and tabular representations. The graphic representation consisted of two histograms that depict two accounts with $\$ 1000$ in each, one earning simple interest and the other earning compound interest. A slider allows users to compare the total amount in the accounts in increments of 1 year up to 30 years. Students use the slider to see the relationships among the original deposit (the principle), time, and the amount of interest earned in each account. As shown by the left histogram in Fig. 5, simple interest does not earn interest on itself because it is not left in the account. In contrast, compound interest does earn interest 
This diagram compares simple interest with compound interest on $\$ 1000$. Use the time line slider to see the relationship among the original deposit (the principle), time, and the amount of interest earned.
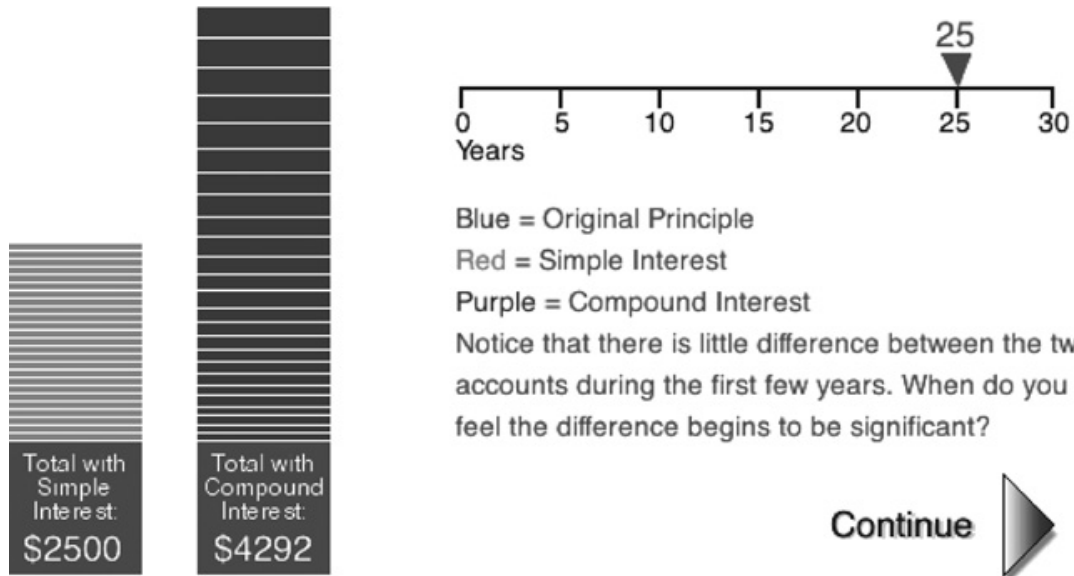

Blue $=$ Original Principle

Red $=$ Simple Interest

Purple $=$ Compound Interest

Notice that there is little difference between the two accounts during the first few years. When do you feel the difference begins to be significant?

\section{Continue}

Fig. 5. A graphic representation of simple (left) and compound (right) interest.

on itself (as revealed by the larger slices in the right histogram) because it is left in the account.

Learners then viewed a pair of accounts-this time with $\$ 6000$ starting principle at $6 \%$ interest-in tabular form covering the first 5 years (Fig. 6). One account shows the growth with simple interest and the other with compound interest. The instructional objective was for students to link the graphical representation with the tabular representation, and use both to select a correct equation for representing how much money they would earn from each account after 5 years.

After making their selection for simple interest among the four equations shown in Fig. 6, students received feedback that the first equation was correct. They then studied the pattern of data illustrating compound interest, selected an equation to represent this pattern of data, and received feedback that Equation 4 was correct (as shown in Fig. 6). Only 7 of the 26 students correctly identified the simple interest formula, and only 10 students correctly identified the compound interest formula, indicating close to chance performance.

Reanalysis of the instruction revealed that there were insufficient links that would enable students to move across the graphic, tabular, and 


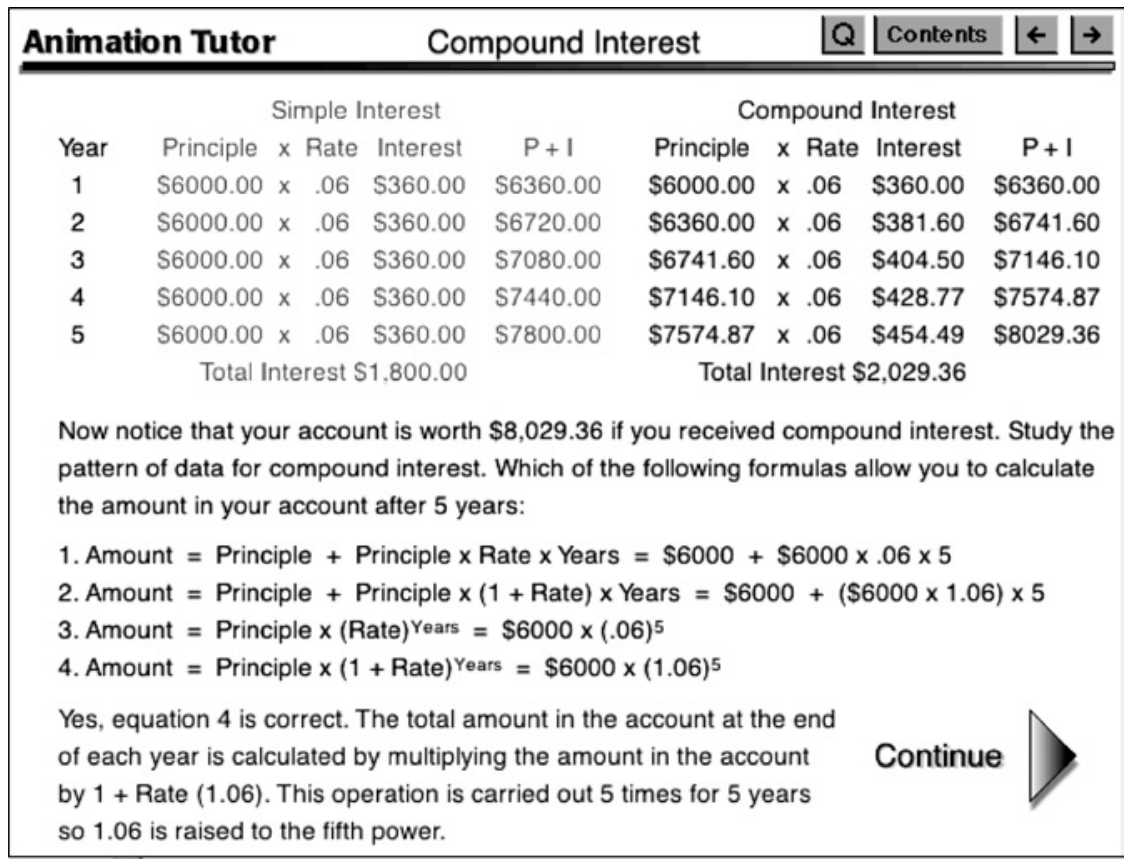

Fig. 6. Selecting an equation to describe earnings from compound interest.

algebraic representations. Figure 7 shows the redesign that brings together the three different representations to reduce the split-attention effect. Both numerical and algebraic representations are represented in the table, and students are required to enter numbers in the table to demonstrate comprehension. They must also click on corresponding entries in the table and in the histogram to establish this connection. The revised instruction therefore provides links that should enable students to make connections across these three different data representations. It also makes this integration manageable by asking a series of questions that require students to attend to only a few elements on the screen at a time (Sweller, 1994).

\section{Replace Ineffective Static Images with Dynamic Images}

Static images can be an effective instructional supplement for text information (Larkin and Simon, 1987). However, sometimes images that are animated or manipulable are more informative. One example is providing 


\begin{tabular}{|c|c|c|c|c|c|c|c|c|}
\hline \multicolumn{3}{|c|}{ Animation Tutor } & \multicolumn{3}{|c|}{ Compound Interest } & \multirow[t]{2}{*}{$Q$} & \multirow[t]{2}{*}{ Contents } & \multirow[t]{2}{*}{$\leftarrow \bigsqcup$} \\
\hline $\mathrm{Ye}$ & Beginning & Amount & Interest & & Ending Ar & & & \\
\hline 1 & $\mathrm{P}$ & $\$ 3000.00$ & $.06 \times P$ & $\$ 180.00$ & $1.06 \mathrm{P}$ & $\$ 3180.00$ & & \\
\hline 2 & $1.06 \mathrm{P}$ & $\$ 3180.00$ & $.06 \times 1.06 \mathrm{P}$ & $\$ 190.80$ & $(1.06)^{2} \mathrm{p}$ & $\$ 3370.80$ & & \\
\hline 3 & $(1.06)^{2} p$ & $\$ 3370.80$ & $.06 \times(1.06)^{2} p$ & $\$ 202.25$ & $(1.06)^{3} \mathrm{p}$ & $\$ 3573.05$ & & \\
\hline 4 & $(1.06)^{3} \mathrm{p}$ & Fill In & $.06 \times(1.06)^{3} \mathrm{p}$ & $\$$ Fill In & $(1.06)^{4} \mathrm{P}$ & Fill In & & \\
\hline 5 & $(1.06)^{4} \mathrm{P}$ & Fill In & $.06 \times(1.06)^{4} \mathrm{P}$ & $\$$ Fill In & $(1.06)^{5} \mathrm{P}$ & Fill In & & \\
\hline
\end{tabular}

Fig. 7. Linking tabular, algebraic, and graphic representations of compound interest.

a diagram to help people discover the convergence solution to Duncker's radiation problem. This solution requires splitting the radiation so its intensity converges at the site of the tumor. A static image that depicted arrows converging toward a circle was ineffective (Gick and Holyoak, 1983), but animation of the arrows to show motion toward the target greatly increased discovery of the convergence solution (Pedone et al., 2001).

Instruction that uses dynamic images seems promising given that static images are ineffective. The ineffectiveness of static images was revealed in a study showing that students often use proportional reasoning inappropriately (Greer, 1993). For instance, students often estimate that it will take a person three times as long to run three miles as it takes the person to run one mile, although fatigue will make that estimated time unlikely. This tendency to apply proportional reasoning uniformly has been found in many studies throughout the world (Verschaffel et al., 2000).

The design of the Dimensional Analysis module attempts to correct students' tendency to inappropriately apply proportional reasoning to area and volume. Students often believe that doubling the length of a side will double the area of a square (which will be 4 times as large) and double the volume of a cube (which will be 8 times as large). Attempts to correct this misconception with static diagrams were largely unsuccessful (De Bock et al., 2002). Brian Greer, Bob Hoffman, and I therefore designed the Dimensional Analysis module so students can virtually manipulate dynamic diagrams of circles, squares, cubes, and irregular figures to learn when proportional reasoning does and does not apply.

The instruction begins with a problem similar to one that students may have previously encountered: Is a 12 -in pizza for $\$ 6.99$ or 20 -in pizza for 


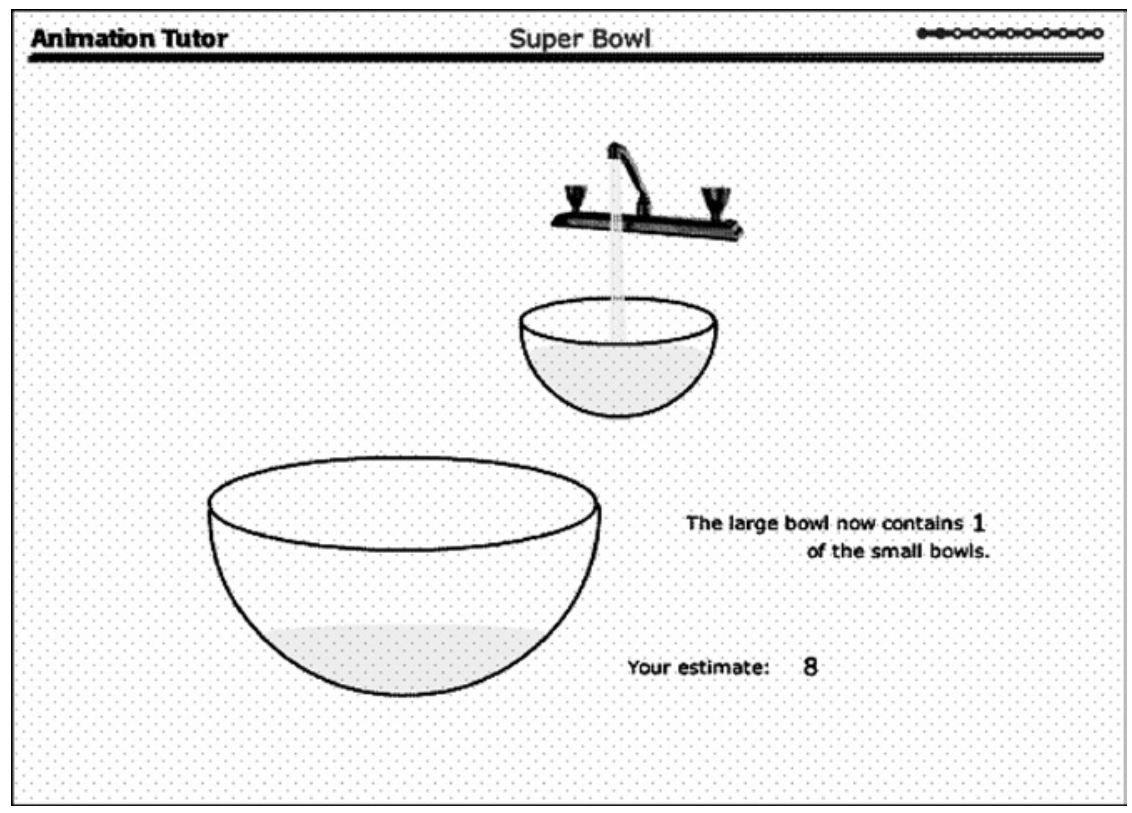

Fig. 8. Estimating how many small bowls will fill a large bowl with twice the radius.

$\$ 12.99$ the better value? Dividing the price by the diameter would result in the false conclusion that the 12-in pizza is the better buy. The Dimensional Analysis module enables students to drag circles with a small diameter onto a circle with a larger diameter so they can better estimate the relative areas of the circles. They can also evaluate their estimates of volume by filling containers. The animation in Fig. 8 allows them to evaluate how much more a (hemispherical) bowl would hold if its radius were doubled. The estimate that it would hold eight of the smaller bowls is correct in this example. Other exercises aid reasoning about squares, cubes, and irregular shapes by manipulating two- and three-dimensional objects.

\section{Provide Domain-Specific Knowledge}

This article began by referring to the American Association for the Advancement of Science's concern that most students in science courses do not possess adequate quantitative knowledge to do well in these courses. A possible remedy is to include science examples among the problems solved in a mathematics class so students can see how mathematics can be applied to science. 
A potential problem in showing the application of mathematical ideas to science is that the application may be meaningless if students do not have a rudimentary understanding of science. One of the conclusions from a review of research on teaching science problem solving is that focusing on general problem solving heuristics, without the construction of an adequate knowledge base, was counterproductive (Taconis et al., 2001). This finding provided a challenge when designing the Chemical Kinetics module to introduce, within a science context, two ideas that are fundamental to the study of calculus. The concept of area under a curve is fundamental to an understanding of integration, and the concept of a tangent to a curve is fundamental to an understanding of differentiation.

Asking students to estimate the percentage of particles that will react by estimating an area under a distribution means little to students who have no background in chemical kinetics. The instruction therefore begins with an introduction to chemical kinetics. Figure 9 shows part of this introduction in which students view how temperature influences the speed (and kinetic energy) of 20 particles.

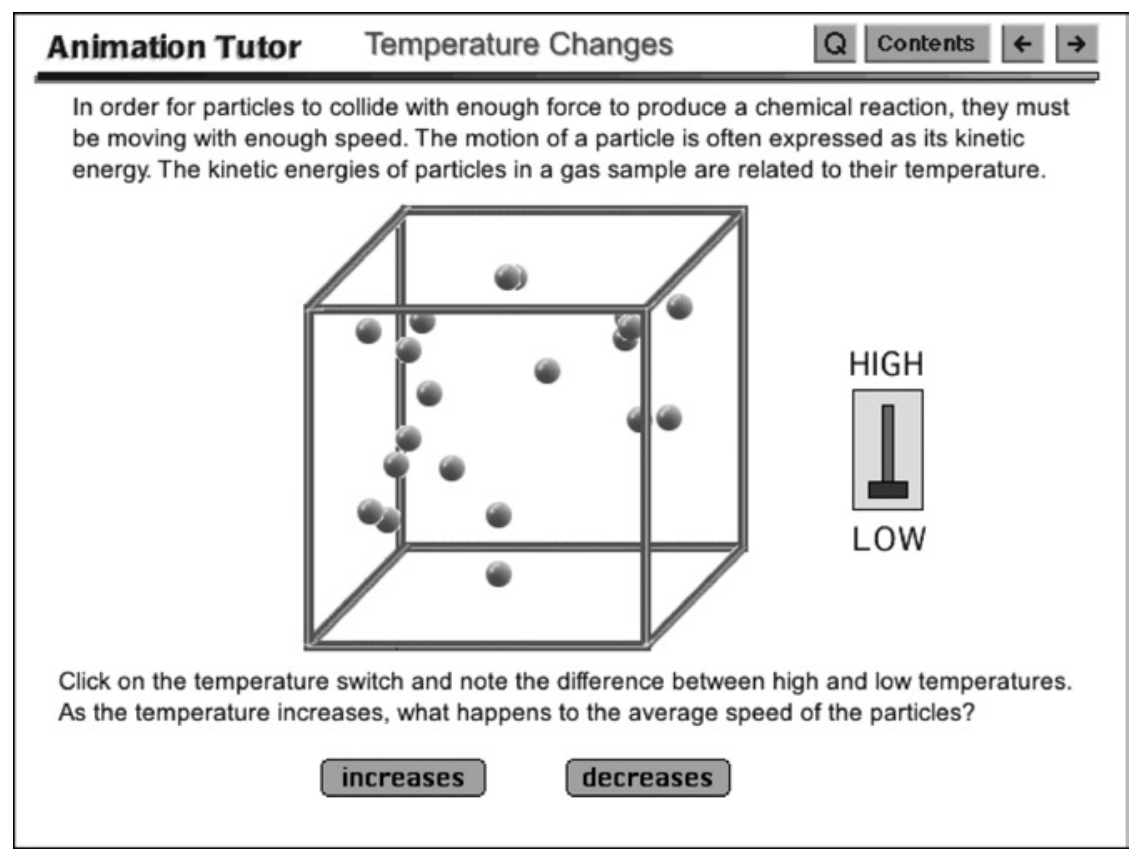

Fig. 9. Simulation of the movement of particles at a low and a high temperature. 


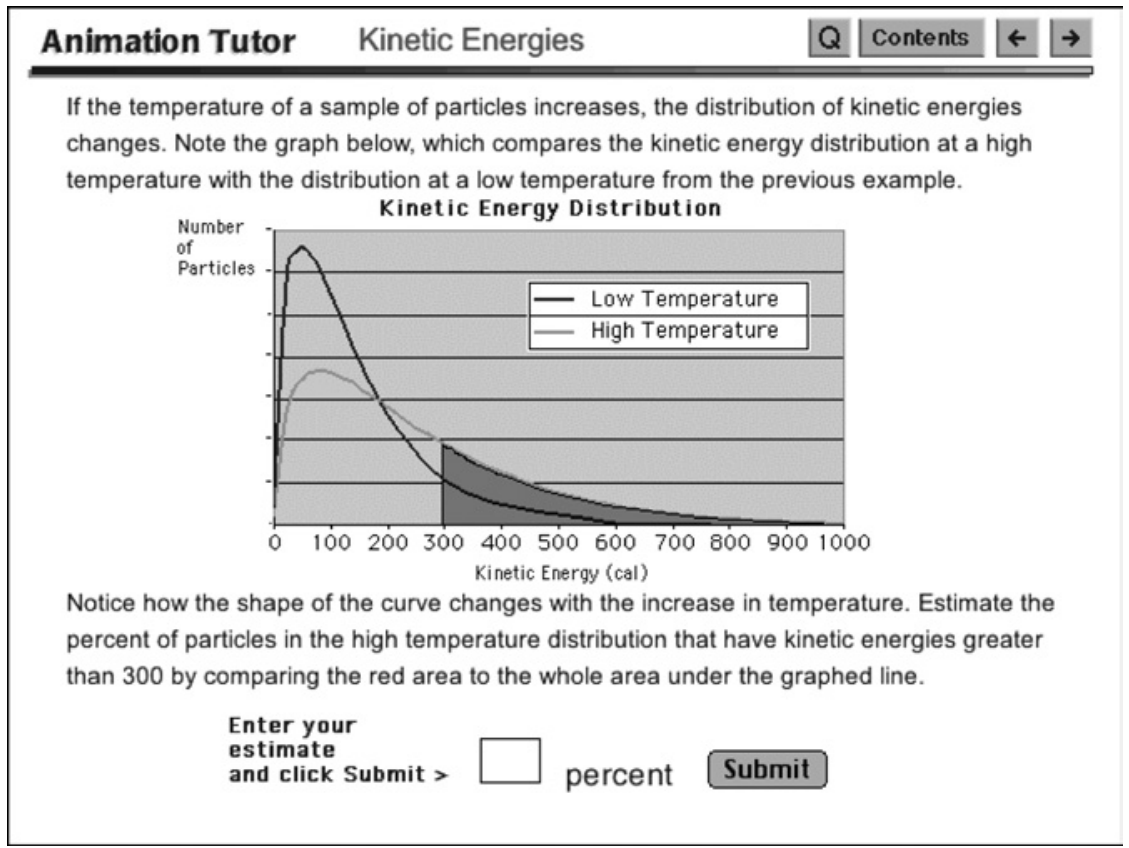

Fig. 10. Distribution of kinetic energies for a low and a high temperature.

\section{FROM RESEARCH TO PRACTICE}

Students next view a histogram of the kinetic energies of the 20 particles to see a simple distribution before studying a more abstract, complex distribution. In order to illustrate the kinetic energy distribution of the millions of atoms or molecules in a real chemical reaction, the instructional program draws a continuous distribution over the histogram. Students are then shown a continuous distribution for a low-temperature reaction and estimate the percentage of particles that exceed the minimum threshold for a reaction. After receiving simulation-based feedback, they make an estimate for a high-temperature reaction, as shown in Fig. 10. Students made accurate predictions. The research reviewed by Taconis et al. (2001) and the importance of domain knowledge in interpreting complex graphs (Roth and Bowen, 2001) suggests that providing instruction on the principles of chemical reactions likely helped students make these predictions.

The instruction on tangents as measures of instantaneous rates of change was less successful. Most students appeared competent in understanding the concept of an average rate of change as represented by the 


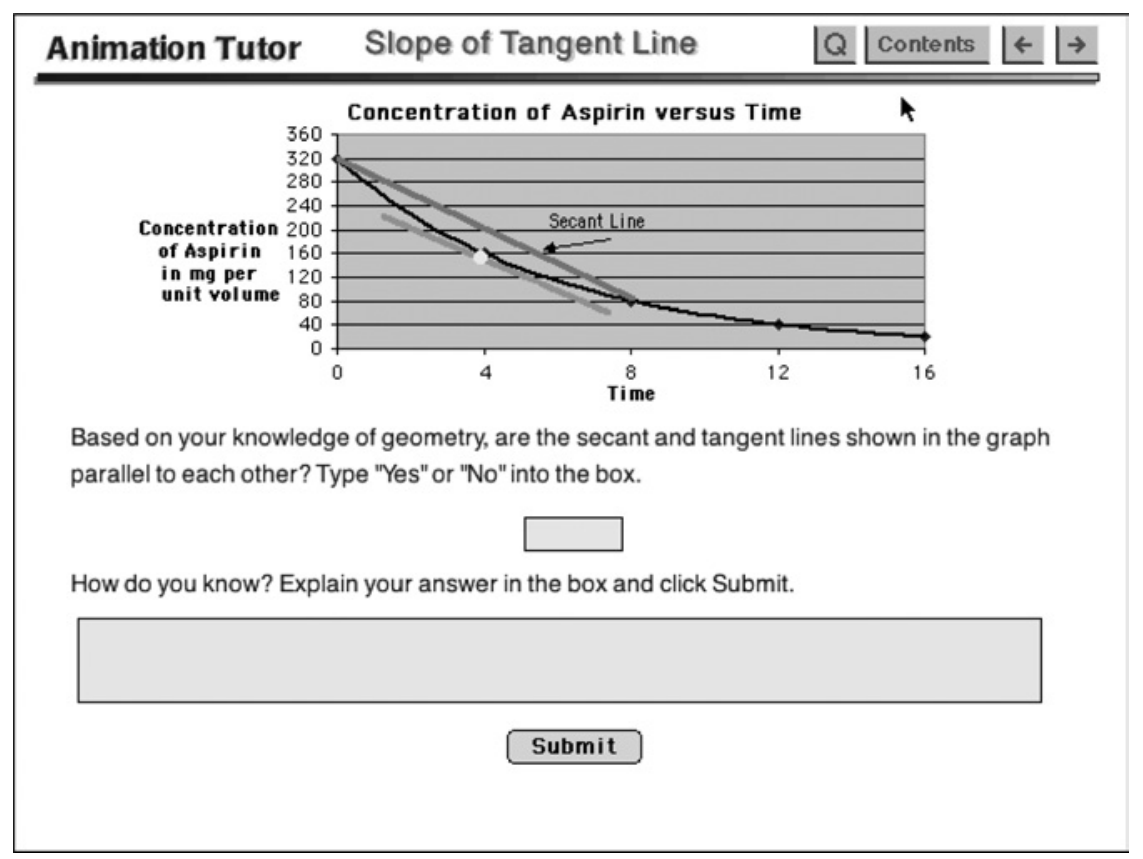

Fig. 11. Comparing average (secant) and instantaneous (tangent) rates of decay.

slope of a secant to the curve. However, many were unable to relate the slope of a secant to an instantaneous slope represented by a tangent, as illustrated in Fig. 11. The instruction showed that the slope of a secant over the interval between 2 and $8 \mathrm{hr}$ is $-30 \mathrm{mg} / \mathrm{hr}$ and the slope of a tangent at the midpoint of the interval is $-27.7 \mathrm{mg} / \mathrm{hr}$. Following this instruction, students were asked: Based on your knowledge of geometry, are the secant and tangent lines shown in the graph parallel to each other? Although this should have been an easy question because students had just been informed that the two lines had different slopes, 11 of 21 students in an introductory calculus course replied that the secant and tangent were parallel.

One possible cause of students' difficulty, as mentioned by Stump (2001), is that they may not integrate the ideas of slope as the steepness of a line and slope as the ratio of rise to run. The Chemical Kinetics module focused on the ratio concept of slope and was weak in integrating this ratio with the steepness of a line. A second possible reason for difficulty, as pointed out by Goldenberg (1988), is that the ratio of rise over run is determined from two points on a curve. This makes it difficult to operationalize the slope of a tangent (in contrast to a secant) because it joins the curve at 
only a single point. Both of these observations likely contributed to students inaccurately reporting that the two lines in Fig. 11 were parallel because they looked parallel. A third possible difficulty in deciding when a tangent is parallel to a secant is students' tendency to overemphasize the importance of the mean in representing data (Cobb, 1999). The formative evaluation indicated that many students have the misconception that a tangent located at the midpoint of the interval is parallel to a secant. We have used the results of the formative evaluation and these potential causes of students' difficulties to redesign this section of the Chemical Kinetics module.

\section{Formative Evaluations}

Students' answers to the questions in the Chemical Kinetics module illustrate the usefulness of formative evaluations to distinguish between successful and unsuccessful instruction. The formative evaluations were conducted at either San Diego State University (SDSU) or at Southwestern College (SWC), a community college south of San Diego. The participants consisted of 25 intermediate algebra students at SWC for the Average Speed module, 35 intermediate algebra students at SWC for the Leaky Tank module, 25 calculus students at SWC for the Kinetics module, 23 introductory psychology students from SDSU for the Personal Finance module, 21 intermediate algebra students at SWC for the Catch Up module, 42 trigonometry students at SWC for the Population Growth module, and 24 prospective elementary teachers at SDSU for the Task Completion module.

The students participated as a class but worked individually at their own computer in a computer-equipped classroom. The session occurred within their standard class period and was related to the course curriculum but was scheduled shortly after the completion of the module, rather than at a time when it would best fit into the course schedule. We plan to schedule future formative evaluations to correspond more closely to specific topics in the curriculum.

The methodology of the formative evaluations shares many similarities with design experiments. Design experiments have emerged as a major topic in the evaluation literature as revealed by special issues of the Educational Researcher (January/February 2003) and the Journal of the Learning Sciences (Issue 1, 2004). Collins (1999) has contrasted laboratory studies with design experiments, respectively, along seven criteria:

- Laboratory setting versus messy situations

- A single dependent variable versus multiple dependent variables

- Controlling variables versus characterizing the situation 
- Fixed procedures versus flexible design revision

- Social isolation versus social interaction

- Testing hypotheses versus developing a profile

- Experimenter versus coparticipant design and analysis

The main goal of formative evaluations is to improve instruction by modifying those parts of the material that are ineffective. Formative evaluations, as with design experiments, evaluate messy situations (the curriculum) that have multiple dependent variables such as the accuracy of estimations, construction of equations, and computations. However, an advantage of evaluating computer-based curricula is that the evaluation of single students interacting with a computer minimizes social interactions and provides more experimenter control of instruction than is possible in more typical classroom settings.

Some proponents of design experiments have argued that theory should play a major role in the design (diSessa and Cobb, 2004; Edelson, 2002). However, in his commentary on the design experiments discussed in the Journal of the Learning Sciences, Dede (2004) argues that testing a modified design to refine theory is not the same as testing a modified design to improve its usability. He therefore asks whether a successful design-based research program should be split into a theory-driven component and a usability component. My answer is "yes." I believe that Collins' (1999) contrast between laboratory studies and design experiments should be taken as an argument for the experimental control of the laboratory in evaluating theory. The following sections show how theoretical questions raised during formative evaluations can be examined in laboratory studies.

\section{Laboratory Studies}

The flow of ideas between research and practice ideally moves in both directions. The work described in the previous sections on curriculum development has raised a number of research questions such as:

- Which strategies do students use to improve their estimates?

- When are animated images more effective than static images?

- How do actions influence algebraic constructions?

Two experiments were conducted on estimating event completion time and address the first two questions (Reed and Hoffman, 2004). Plans for addressing the third question are underway and also described. 


\section{Which Strategies do Students use to Improve Their Estimates?}

One of the objectives of the Animation Tutor project is to improve estimation skills by providing visual feedback on students' estimates. For example, if a student estimated that it would take $5 \mathrm{hr}$ to fill a tank and the tank appeared $70 \%$ full after a simulation of $5 \mathrm{hr}$, she could use this feedback to improve her estimate. Reed et al.'s (2002) formative evaluation of the Task Completion module revealed that students did improve their estimates over three trials. It is unknown, however, which strategies students used and whether the inclusion of a digital clock and an overflow tank (as in Fig. 1) improved their estimates.

In order to experimentally control the initial simulation used as the basis for revision, students were shown 3 -sec simulations that filled either $.5, .6, .7, .8, .9,1.1,1.2,1.3,1.4$, or 1.5 tanks for a simulated time of $6 \mathrm{hr}$ (Reed and Hoffman, 2004). Students viewed simulations with the presence or absence of a digital clock and with the presence or absence of an overflow tank. They then estimated how long it would take to fill 1.0 tank. Figure 12 shows the screen at the end of a simulation when (A) both the clock and overflow tank are present and when (B) both the clock and overflow tank are absent.

Students' estimates and verbal reports revealed that they used a variety of sophisticated estimation strategies. Table II displays these strategies. The proportional volume strategy divides the time to fill part of the tank by the proportion of the tank filled. If it takes $6 \mathrm{hr}$ to fill .8 tanks, it will take $7.5 \mathrm{hr}$ to fill 1.0 tank. In contrast, the temporal extrapolation strategy uses temporal information (fill rate) to infer how much more time is required to complete the task. It will take 2 more hours to fill a tank if the water rises at a rate of .15 tanks per hour and the tank is $70 \%$ full. The fill time strategy is simply to check the clock when the tank is exactly full on those trials in which there is an overflow. Reed and Hoffman (2004) investigated the use of a fourth (mental simulation) strategy in a second experiment. Table II shows

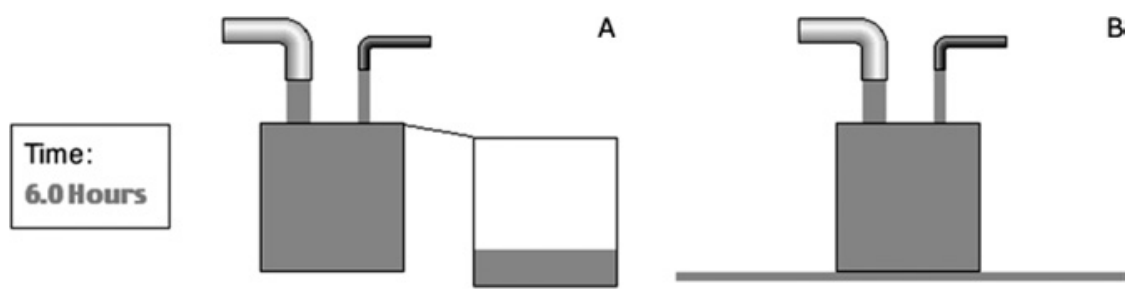

Fig. 12. Example of a display showing 1.2 tanks filled for the Clock \& Tank condition (A) and the No Aids (B) condition. 
Table II. Alternative Strategies for Estimating Event Completion Times (Reed and Hoffman, 2004)

\begin{tabular}{|c|c|c|c|}
\hline Strategy & Perceptual demands & Arithmetic demands & Helpful aids \\
\hline $\begin{array}{l}\text { Proportional } \\
\text { volume }\end{array}$ & $\begin{array}{l}\text { Estimate the } \\
\text { proportion of } \\
\text { tank(s) filled } \\
\text { including the } \\
\text { overflow tank }\end{array}$ & $\begin{array}{l}\text { Divide the time by } \\
\text { the proportion of } \\
\operatorname{tank}(\mathrm{s}) \text { filled }\end{array}$ & $\begin{array}{l}\text { Overflow tank on } \\
\text { overfill problems }\end{array}$ \\
\hline $\begin{array}{l}\text { Temporal } \\
\text { extrapolation }\end{array}$ & $\begin{array}{l}\text { Estimate the rate of } \\
\text { fill and the } \\
\text { unfilled volume }\end{array}$ & $\begin{array}{l}\text { Divide unfilled } \\
\text { volume by the } \\
\text { rate to determine } \\
\text { additional time } \\
\text { required to fill the } \\
\text { tank }\end{array}$ & $\begin{array}{l}\text { Clock on underfill } \\
\text { problems }\end{array}$ \\
\hline Fill time & $\begin{array}{l}\text { Check clock for time } \\
\text { when tank is } \\
\text { exactly full }\end{array}$ & None & $\begin{array}{l}\text { Clock on overfill } \\
\text { problems }\end{array}$ \\
\hline $\begin{array}{l}\text { Mental } \\
\text { simulation }\end{array}$ & $\begin{array}{l}\text { Mentally simulate } \\
\text { the current fill } \\
\text { rate until the tank } \\
\text { is full }\end{array}$ & $\begin{array}{l}\text { Add the mental } \\
\text { simulation time to } \\
\text { the time to } \\
\text { partially fill tank }\end{array}$ & $\begin{array}{l}\text { Clock on underfill } \\
\text { problems }\end{array}$ \\
\hline
\end{tabular}

the perceptual demands, arithmetic demands, and predicted facilitation of two visual aids for each of the strategies.

The results of the first experiment revealed that both the digital clock and overflow tank improved estimates, confirming the decision to include both in the Task Completion module. The facilitating effect of both a digital clock to calibrate time and an overflow tank to calibrate volume supports the use of both temporal and spatial strategies. In addition, students' verbal reports of strategies indicated that they were fairly evenly divided in their choice of a spatial strategy or a temporal strategy.

The most surprising aspect of the results was the pattern of correlations between the estimation task and three other tasks that measured arithmetic, temporal, and spatial abilities. The arithmetic task contained problems that were identical to the ones used in the estimation task except that they were stated verbally: If it takes $6 \mathrm{hr}$ to fill 0.8 tanks, how long will it take to fill 1.0 tank. The spatial task required estimating how much liquid was in the tank (such as 0.8 tanks), and the temporal task required judging the time on the clock when the tank was exactly full. We expected the arithmetic task to produce the highest correlation because of the similarity of the problems and because we thought mental calculation was the limiting factor in producing accurate estimates. Although this correlation $(r=0.34)$ was reliable, it was less predictive than the spatial estimates $(r=0.51)$. This finding confirms that perceptual abilities play a major role in many reasoning tasks (Ackerman and Cianciolo, 2000). This distinction between numerical and spatial skills is important because principle components analysis of a 
variety of mathematical reasoning (psychometric) tests found two principle components: one related to computational estimation and the other related to numerosity and measurement estimation that could be based on spatial ability (Hogan and Brezinski, 2003).

\section{When Are Animated Images More Effective Than Static Images?}

One of the primary instructional objectives of the Animation Tutor project is to replace static images with animated images when necessary. The challenge, of course, is identifying when it is necessary. Animated images, for instance, are not necessary for using the proportional volume strategy because this strategy does not use temporal information. It only uses the proportion of the tank filled at the end of the simulation.

The proportional volume strategy should be effective when there is no change in the rate of fill as in Experiment 1 but should be less effective if there is a change in fill rate. Animated images should therefore be more effective when a leak in the side of the tank decreases the rate of fill or when a delay in one of the pipes later increases the rate of fill. Reed and Hoffman (2004) tested this prediction in a second experiment by using two types of problems (no-leak and bottom-leak) in which there was no change in fill rate, and two types of problems (side-leak and delay) in which there was a change in fill rate.

The sequence of animated images was accompanied by instruction to use the mental simulation strategy shown in Table II. Students were told to mentally simulate the filling of the tank at the current rate when the physical simulation stopped (there were no overflow problems in this experiment). When their mental simulation reached the top of the tank, students pressed a response key that timed the accuracy of their simulations. Reed and Hoffman's (2004) finding that estimates of task completion times were more accurate than the mental simulation times indicates that the mental simulations were not the only source of information used to make the estimates.

An encouraging aspect of these findings is that most students showed good judgment in how they used the three information sources (problem statement, static diagram, animated diagram) to produce fairly accurate estimates of event completion time. Students' ratings of how they used this information across the four types of problems indicated that they relied less on the static diagram and more on the problem text or the animation when there were rate changes. An analysis of the estimates revealed a Sequence $x$ Problem interaction in which students gave more accurate estimates if they saw the animated problems first, but the degree of improvement depended on the problem type. These data support the notion that people use multiple cues to derive an estimate, and weight each cue according to its predictive accuracy relative to alternative cues (Brown and Siegler, 1993). 


\section{How Do Actions Influence Algebraic Constructions?}

Attempts to improve the linking of graphics, tables, and equations in the simple and compound interest examples led Bob Hoffman and me to examine whether the representations could be better coordinated for other examples in the Personal Finance module. We incorporated the following problem that required investing $\$ 10,000$ :

You can put your money in a 5-year Certificate of Deposit (CD) that pays 6\% interest, but you also want to keep some money in a regular savings account in case you need cash for an emergency. The savings account pays 3.5\% interest. Estimate how much money you should invest in the CD in order to earn $\$ 500$ interest between the two accounts during the first year.

Figure 13 shows the initial iconic representation of the problem in which students were asked to drag money from one $\$ 5000$ stack to the other $\$ 5000$ stack to estimate the amount of money in each account that would earn $\$ 500$ in total interest. Students had three attempts to improve their estimates by clicking on "Check Your Estimate" to receive feedback on their accuracy.

The next part of the instruction showed students how they could use algebra to construct an equation for solving the problem. The instruction

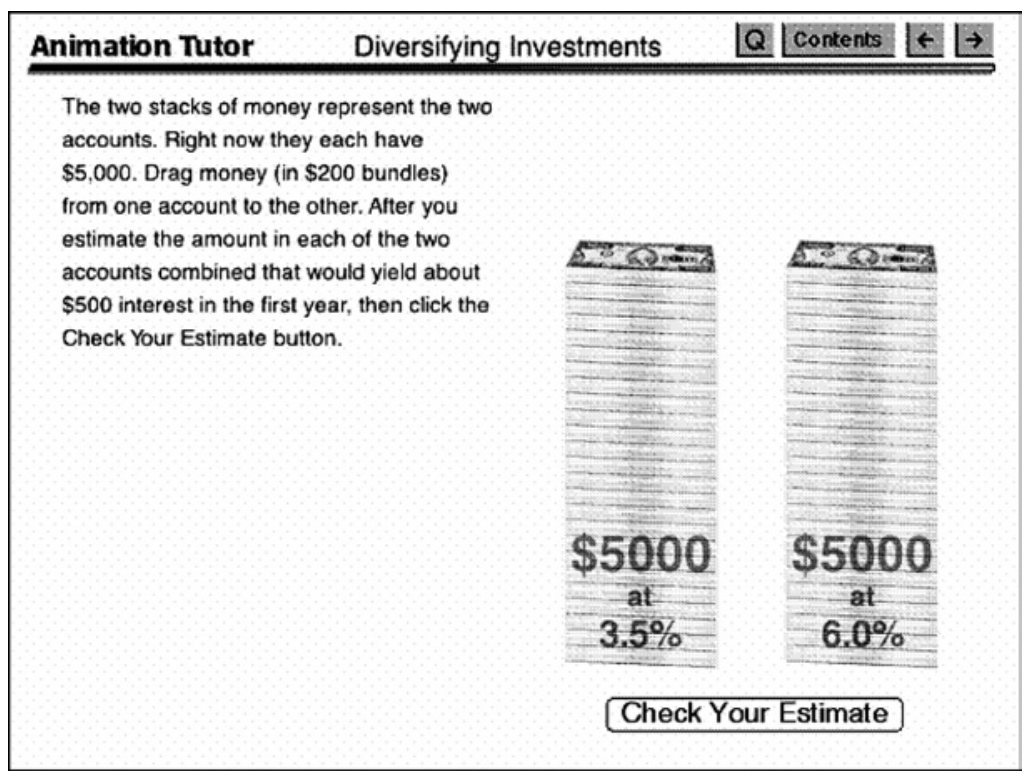

Fig. 13. Distributing money between a $3.5 \%$ checking account and a $6 \% \mathrm{CD}$ account to earn $\$ 500$ in interest. 
began by asking how much money would be in the savings account if $A$ represented the amount of money in the $\mathrm{CD}$ account. Understanding this relation is useful for constructing the standard equation for solving the problem: $A \times .06+(\$ 10,000-A) \times .035=\$ 500$. Sixteen of the 26 students correctly selected $\$ 10,000-A$, eight students selected $\$ 10,000+A$, and two students selected $\$ 10,000 \times A$.

Reexamination of this instruction revealed that the iconic portrayal of the money in the estimation task did not match the algebraic representation. The algebraic representation suggests that one starts with a stack of $\$ 10,000$ and removes $A$ from this stack. The iconic representation of transferring $A$ from one stack of $\$ 5000$ to another stack of $\$ 5000$ can be represented algebraically as: $(\$ 5000-A) \times .035+(\$ 5000+A) \times .06=\$ 500$. This equation can also be solved for $A$ but $A$ now represents the amount of money transferred $(\$ 1000)$ from the savings account to the CD account.

We plan to investigate whether a more coordinated portrayal of actions and algebraic representations would improve the construction of algebraic representations. The current portrayal, shown in Fig. 13, would serve as the control condition. The modified representation would be consistent with the algebraic representation by showing a single stack of bills representing $\$ 10,000$ in the savings account. Transferring $A$ from the savings account would then more closely correspond to the algebraic representation of $\$ 10,000-A$ in this account. Problems from the other modules will be added to the experimental and control conditions to provide generality for learning how actions influence mathematical reasoning.

In conclusion, this personal case study illustrated the reciprocal relationship between research and practice. We used research to build the Animation Tutor curriculum, formatively evaluated the curriculum in classroom settings, and conducted research to answer theoretical questions raised during formative evaluation. Hopefully, the work conducted on the animation tutor project will help researchers and practitioners further realize and benefit from the reciprocal relationship between research and practice.

\section{ACKNOWLEDGMENTS}

I am thankful for the helpful comments of Kenneth Kiewra, Dan Robinson, and anonymous reviewers on earlier versions of this article. Partial support for this work was provided by the National Science Foundation's Course, Curriculum and Laboratory Improvement Program under grant DUE-9950746 (An animation-based tutor for algebra word problems). Any opinions, findings, and conclusions or recommendations expressed in this material are those of the author(s) and do not 
necessarily reflect the views of the National Science Foundation. The project web site, including demonstrations and experiments, can be accessed at http://www.sci.sdsu.edu/mathtutor/.

\section{REFERENCES}

Ackerman, P. L., and Cianciolo, A. T. (2000). Cognitive, perceptual-speed, and psychomotor determinants of individual differences during skill acquisition. J. Exp. Psychol.: Appl. 6: 259-290.

Ainsworth, S. (1999). The functions of multiple representations. Comp. Educ. 33: 131-152.

Barnett, S. M., and Ceci, S. J. (2002). When and where do we apply what we learn? A taxonomy of far transfer. Psychol. Bull. 128: 612-637.

Brown, N. R., and Siegler, R. S. (1993). Metrics and mappings: A framework for understanding real-world quantitative estimation. Psychol. Rev. 100: 511-534.

Chen, Z. (1995). Analogical transfer: From schematic pictures to problem solving. Memory Cogn. 23: 255-269.

Cobb, P. (1999). Individual and collective mathematical development: The case of statistical data analysis. Math. Think. Learn. 1: 5-43.

Collins, A. (1999). The changing infrastructure of education research. In Lagemann, L., and Shulman, L. (eds.), Issues in education research, Josey-Bass, San Francisco.

De Bock, D., Verschaffel, L., and Janssens, D. (2002). The effects of different problem presentations and formulations on the illusion of linearity in secondary school students. Math. Think. Learn. 4: 65-89.

Dede, C. (2004). If design-based research is the answer, what is the question? J. Learn. Sci. 13: 105-114.

diSessa, A. A., and Cobb, P. (2004). Ontological innovation and the role of theory in design experiments. J. Learn. Sci. 13: 77-103.

Edelson, D. C. (2002). Design research: What we learn when we engage in design. J. Learn. Sci. 11: 105-121.

Gick, M., and Holyoak, K. J. (1983). Schema induction and analogical transfer. Cogn. Psychol. 15: $1-38$.

Goldenberg, E. P. (1988). Mathematics, metaphors, and human factors: Mathematical, technical, and pedagogical challenges in the educational use of graphical representation of functions. J. Math. Behav. 7: 135-173.

Goldstone, R. L., and Sakamota, Y. (2002). The transfer of abstract principles governing complex adaptive systems. Cogn. Psychol. 46: 414-466.

Greer, B. (1993). The mathematical modeling perspective on wor(1)d problems. J. Math. Behav. 12: 239-250.

Greer, B., Hoffman, B., and Reed, S. K. (2002). Animation Tutor: Dimensional thinking. [Computer software]. San Diego State University, San Diego, CA.

Greeno, J. G., Smith, D. R., and Moore, J. L. (1993). Transfer of situated learning. In Detterman, D. K., and Sternberg, R. J. (eds.), Transfer on Trial: Intelligence, Cognition, and Instruction, Ablex, Norwood, NJ, pp. 99-167.

Hoffman, B., and Reed, S. K. (2001). Animation Tutor: Personal finance. [Computer software]. San Diego State University, San Diego, CA.

Hogan, T. P., and Brezinski, K. L. (2003). Quantitative estimation: One, two, or three abilities? Math. Think. Learn. 5: 259-280.

Jonassen, D. H. (2003). Designing reseach-based instruction for story problems. Educ. Psychol. Rev. 15: 267-296.

Koedinger, K. R., and Tabachneck, H. J. (1994). Two strategies are better than one: Multiple strategy use in word problem solving. Paper presented at the Annual Meeting of the American Educational Research Association, New Orleans, LA. 
Larkin, J. H., and Simon, H. A. (1987). Why a diagram is (sometimes) worth ten thousand words. Cognitive Science 11: 65-99.

Mayer, R. E. (2001). Multimedia Learning, Cambridge University Press, Cambridge, UK.

NCTM. (2000). Principles and standards for school mathematics, National Council of the Teacher of Mathematics, Reston, VA.

Pedone, R., Hummel, J. E., and Holyoak, K. J. (2001). The use of diagrams in analogical problem solving. Memory Cogn. 19: 214-221.

Project 2061. (2000). Algebra for all-Not with today's textbooks, says AAAS (Retrieved April 16, 2002, from www.project2061.org/newsinfo/press/r1000426.htm): American Association for the Advancement of Science.

Reed, S. K. (1984). Estimating answers to algebra word problems. J. Exper. Psychol. Learn. Memory Cogn. 10: 778-790.

Reed, S. K. (1985). Effect of computer graphics on improving estimates to algebra word problems. J. Educ. Psychol. 77: 285-298.

Reed, S. K. (1987). A structure-mapping model for word problems. J. Exp. Psychol. Learn. Memory Cogn. 13: 124-139.

Reed, S. K. (1993). A schema-based theory of transfer. In Detterman, D. K., and Sternberg, R. J. (eds.), Transfer on trial: Intelligence, Cognition, and Instruction, Ablex, Norwood, NJ, pp. 39-67.

Reed, S. K. (1999). Word Problems: Research and Curriculum Reform, Erlbaum, Mahwah, NJ.

Reed, S. K., Cooke, J., and Jazo, L. (2002). Building complex solutions from simple solutions in the Animation Tutor: Task Completion. Math. Think. Learn. 4: 315-336.

Reed, S. K., and Evans, A. C. (1987). Learning functional relations: A theoretical and instructional analysis. J. Exp. Psychol. Gen. 116: 106-118.

Reed, S. K., and Hoffman, B. (2004). Use of temporal and spatial information in estimating event completion time. Memory Cogn. 32: 271-282.

Reed, S. K., and Jazo, L. (2002). Using multiple representations to improve conceptions of average speed. J. Educ. Comput. Res. 27: 147-166.

Reed, S. K., Hoffman, B., and Phares, S. (2001). Animation Tutor: Catch up. [Computer software]. San Diego State University, San Diego, CA.

Reed, S. K., Hoffman, B., and Short, D. (2002). Animation Tutor: Population growth. [Computer software]. San Diego State University, San Diego, CA.

Reed, S. K., and Phares, S. (2003). Animation Tutor: Task completion. [Computer software]. San Diego State University, San Diego, CA.

Reed, S. K., Phares, S., and Sale, J. (2003). Animation Tutor: Leaky tanks. [Computer software]. San Diego State University, San Diego, CA.

Reed, S. K., and Saavedra, N. C. (1986). A comparison of computation, discovery, and graph procedures for improving students' conception of average speed. Cogn. Instruct. 3: 31-62.

Reed, S. K., Sale, J., and Phares, S. (2000). Animation Tutor: Average speed. [Computer software]. San Diego State University, San Diego, CA.

Rieber, L. P. (1990). Animation in computer-based instruction. Educ. Technol. Res. Dev. 38 : 77-86.

Roth, W.-M., and Bowen, G. M. (2001). Professionals read graphs: A semiotic analysis. J. Res. Math. Educ. 32: 159-194.

Stump, S. L. (2001). High school precalculus students' understanding of slope as measure. School Sci. Math. 10: 81-89.

Sweller, J. (1994). Cognitive load theory, learning difficulty, and instructional design. Learn. Instruct. 4: 295-312.

Taconis, R., Ferguson-Hessler, M. G. M., and Broekkamp, H. (2001). Teaching science problem solving: An overview of experimental work. J. Res. Sci. Teach. 38: 442-468.

Tyner, K., Reed, S. K., and Phares, S. (2000). Animation Tutor: Chemical kinetics. [Computer software]. San Diego State University, San Diego, CA.

Tversky, B., Morrison, J. B., and Betrancourt, M. (2002). Animation: Can it facilitate? Int. J. Hum.-Comp. Stud. 57: 1-16.

Verschaffel, L., Greer, B., and de Corte, E. (Eds.). (2000). Making Sense of Word Problems, Swets \& Zeitlinger, Heereweg, The Netherlands. 
Copyright of Educational Psychology Review is the property of Kluwer Academic Publishing and its content may not be copied or emailed to multiple sites or posted to a listserv without the copyright holder's express written permission. However, users may print, download, or email articles for individual use. 